\title{
Correction to: Hypophosphatasia: Canadian update on diagnosis and management
}

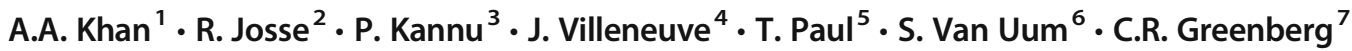 \\ Published online: 29 May 2019 \\ (C) International Osteoporosis Foundation and National Osteoporosis Foundation 2019
}

\section{Correction to: Osteoporosis International https://doi.org/10.1007/s00198-019-04921-y}

In the article mentioned above an author's name was misspelled.

The correct author name reads as follows:

S. Van Uum

We apologize for the inconvenience.

Publisher's note Springer Nature remains neutral with regard to jurisdictional claims in published maps and institutional affiliations.

The online version of the original article can be found at https://doi.org/ 10.1007/s00198-019-04921-y

\section{A.A. Khan}

aliya@mcmaster.ca

1 McMaster University, 1280 Main St W, Hamilton, ON L8S 4L8, Canada

2 St. Michael's Hospital and University of Toronto, Toronto, Canada

3 Hospital for Sick Kids, Toronto, Canada

4 Le Centre Hospitalier Universitaire de Quebec, Quebec, Canada

5 St. Joseph's Health Care London, London, Ontario, Canada

6 Western University, London, Canada

7 Health Sciences Centre Winnipeg, Winnipeg, Canada 